\title{
Identification of a laccase Glac15 from Ganoderma lucidum 77002 and its application in bioethanol production
}

\author{
Zemin Fang ${ }^{1,2}$, Xiaoman Liu ${ }^{1,2}$, Liyuan Chen ${ }^{3}$, Yu Shen ${ }^{3}$, Xuecheng Zhang ${ }^{1,2}$, Wei Fang ${ }^{1,2}$, Xiaotang Wang ${ }^{4}$,
} Xiaoming $\mathrm{Bao}^{3^{*}}$ and Yazhong Xiao ${ }^{1,2^{*}}$

\begin{abstract}
Background: Laccases have potential applications in detoxification of lignocellulosic biomass after thermochemical pretreatment and production of value-added products or biofuels from renewable biomass. However, their application in large-scale industrial and environmental processes has been severely thwarted by the high cost of commercial laccases. Therefore, it is necessary to identify new laccases with lower cost but higher activity to detoxify lignocellulosic hydrolysates and better efficiency to produce biofuels such as bioethanol. Laccases from Ganoderma lucidum represent proper candidates in processing of lignocellulosic biomass.
\end{abstract}

Results: G. lucidum 77002 produces three laccase isoenzymes with a total laccase activity of $141.1 \mathrm{U} / \mathrm{mL}$ within 6 days when using wheat bran and peanut powder as energy sources in liquid culture medium. A new isoenzyme named Glac15 was identified, purified, and characterized. Glac15 possesses an optimum pH of 4.5 to 5.0 and a temperature range of $45^{\circ} \mathrm{C}$ to $55^{\circ} \mathrm{C}$ for the substrates tested. It was stable at pH values ranging from 5.0 to 7.0 and temperatures lower than $55^{\circ} \mathrm{C}$, with more than $80 \%$ activity retained after incubation for $2 \mathrm{~h}$. When used in bioethanol production process, $0.05 \mathrm{U} / \mathrm{mL}$ Glac15 removed $84 \%$ of the phenolic compounds in prehydrolysate, and the yeast biomass reached 11.81 (optimal density at $600 \mathrm{~nm}\left(\mathrm{OD}_{600}\right)$ ), compared to no growth in the untreated one. Addition of Glac15 before cellulase hydrolysis had no significant effect on glucose recovery. However, ethanol yield were improved in samples treated with laccases compared to that in control samples. The final ethanol concentration of $9.74,10.05,10.11$, and $10.81 \mathrm{~g} / \mathrm{L}$ were obtained from samples containing only solid content, solid content treated with Glac15, solid content containing $50 \%$ prehydrolysate, and solid content containing 50\% prehydrolysate treated with Glac15, respectively.

Conclusions: The G. lucidum laccase Glac15 has potentials in bioethanol production industry.

Keywords: Laccase, Ganoderma lucidum, Identification, Characterization, Bioethanol, Detoxification

\section{Background}

Bioethanol production from renewable biomass such as lignocellulosic materials has been the focus of numerous contemporary investigations with the decreasing supply of fossil fuels and the increasing environmental concerns associated with them [1]. Lignocellulosic feed stocks such as sugar cane bagasse and corn stover are cheap,

\footnotetext{
*Correspondence: bxm@sdu.edu.cn; yzxiao@ahu.edu.cn

${ }^{3}$ The State Key Laboratory of Microbial Technology, School of Life Sciences, Shandong University, 27 Shanda Nanlu, Jinan, Shandong 250100, China

'School of Life Sciences, Anhui University, 111 Jiulong Road, Hefei, Anhui 230601, China

Full list of author information is available at the end of the article
}

renewable, and abundant in nature. They do not compete with food production and contribute to reduce the use of fossil fuels, thus alleviating carbon dioxide emission and global warming [1]. Lignocellulosic feed stocks mainly consist of two polysaccharides, cellulose and hemicellulose, which can be hydrolyzed to provide monosaccharides used by microbial biocatalysts in fermentation processes $[2,3]$. Unfortunately, cellulose and hemicellulose are closely linked by lignin, a polymer that acts as cementing agent between cellulose fibers [2]. Lignocellulosic materials are thus recalcitrant to hydrolysis

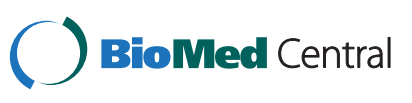

(c) 2015 Fang et al.; licensee BioMed Central. This is an Open Access article distributed under the terms of the Creative Commons Attribution License (http://creativecommons.org/licenses/by/4.0), which permits unrestricted use, distribution, and reproduction in any medium, provided the original work is properly credited. The Creative Commons Public Domain Dedication waiver (http://creativecommons.org/publicdomain/zero/1.0/) applies to the data made available in this article, unless otherwise stated. 
and require pretreatment before being converted to bioethanol $[3,4]$.

The combination of steam explosion and acidic catalyst such as $\mathrm{H}_{2} \mathrm{SO}_{4}$ or $\mathrm{SO}_{2}$ is one of the most commonly used methods for lignocellulose pretreatment, since it breaks and/or removes a minor part of lignin, depolymerizes cellulose and hemicellulose, and makes the biomass more accessible to hydrolytic enzymes with relatively lower cost [5]. However, this pretreatment generates some soluble inhibitory compounds from partial degradation of sugars and lignin, which can affect enzymatic hydrolysis as well as fermentation steps, and will reduce the ethanol productivity of the microorganisms and the final ethanol yield $[2,3,5]$.

The inhibitory compounds generated during the pretreatment process include weak acids, furan derivatives, and phenolic and other compounds [2]. Several procedures for the removal of these compounds including biological, physical, and chemical methods have been assayed. Among which, enzymatic treatment using laccases has been suggested as one of the most promising approach in lignocellulosic biomass detoxification [3,5]. Laccases (benzenediol:oxygen oxidoreductases, EC1.10.3.2) are a family of blue multicopper oxidases that are capable of oxidizing a wide range of phenolic and aromatic compounds, with concomitant reduction of molecular oxygen to water [6]. When detoxifying the lignocellulosic hydrolysate, laccase was suggested to be selective and can virtually remove all phenolic monomers. Compared with other approaches, advantages of using laccase are that enzyme preparations have higher catalytic efficiencies, fewer toxic subproducts, shorter treatment time, and lower energy costs $[3,5,7]$. The disadvantage of using laccase is the high enzyme production costs, as the commercial laccases are still expensive despite strides made to reduce enzyme cost through modern biotechnology, thus restricting the applications of laccases [3]. Screening for laccases with higher lignocellulosic hydrolysate-detoxifying ability may improve the present situation.

Laccases are widespread in white-rot fungi. Among which, Ganoderma lucidum is a representative that is able to grow on withered wood and other agro-lignocellulosic biomass materials and can decompose lignin by secreting enzymes such as laccases [8]. For instance, G. lucidum is one of the richest set of wood degradation enzymes among all of the sequenced basidiomycetes [9]. Based on this, and the fact that G. lucidum can produce high amount of laccase in liquid cultures [10-12], laccases from this fungus may promote degradation/modification of lignin or lignin-derived components [13] and therefore represent proper candidates in processing lignocellulosic biomass. To address this issue, a fungal strain G. lucidum 77002 was investigated for laccase production by using agricultural by-products as media, and a laccase identified as Glac15 was purified and characterized for the first time; its application potential in lignocellulosic biomass detoxification after thermochemical pretreatment was also evaluated. Our results indicated that Glac15 is a promising candidate in bioethanol production.

\section{Results and discussion}

\section{Laccase production in liquid culture}

Wheat and peanut are two of the most common agricultural crops in China. To obtain laccases with lower cost, along with the fact that wheat bran can induce high amount of lignocellulose-degrading enzymes including laccase in liquid culture [14], wheat bran (3\% dry weight, $w / v)$ and peanut powder (3\% dry weight, $w / v)$ were used as energy sources to induce G. lucidum 77002 to produce laccase. Laccase activity reached $141.1 \pm 0.2 \mathrm{U} / \mathrm{mL}$ within 6 days when assayed using 2,2'-azino-bis-(3-ethylbenzothiazoline-6-sulfonic acid) (ABTS) as a substrate (Figure 1), indicating that these agriculture by-products could effectively induce laccase production. This is consistent with previous reports that other agriculture and forest by-products such as pine and poplar ground woods [10] and wheat bran [14] can induce laccase production in G. lucidum, which were 0.93 and $97.34 \mathrm{U} / \mathrm{mL}$, respectively. Besides, tamarind shell with ethanol $(3 \%, v / v)$, $\mathrm{CuSO}_{4}(0.4 \mathrm{mM})$, and gallic acid $(1 \mathrm{mM})$-containing medium can also induce the G. lucidum laccase production, yielding about $74.84 \mathrm{U} / \mathrm{mL}$ laccase activity after 15 days, which was 416 times higher than the control [15]. However, a different laccase zymography was shown according to culture conditions. As indicated by native polyacrylamide gel electrophoresis (PAGE), G. lucidum 77002 produced three laccase isoforms in this study (Figure 2a), whereas a G. lucidum strain produced only two laccase isoenzymes in high-nitrogen culture and in cultures containing both poplar and pine [10]. In contrast to these

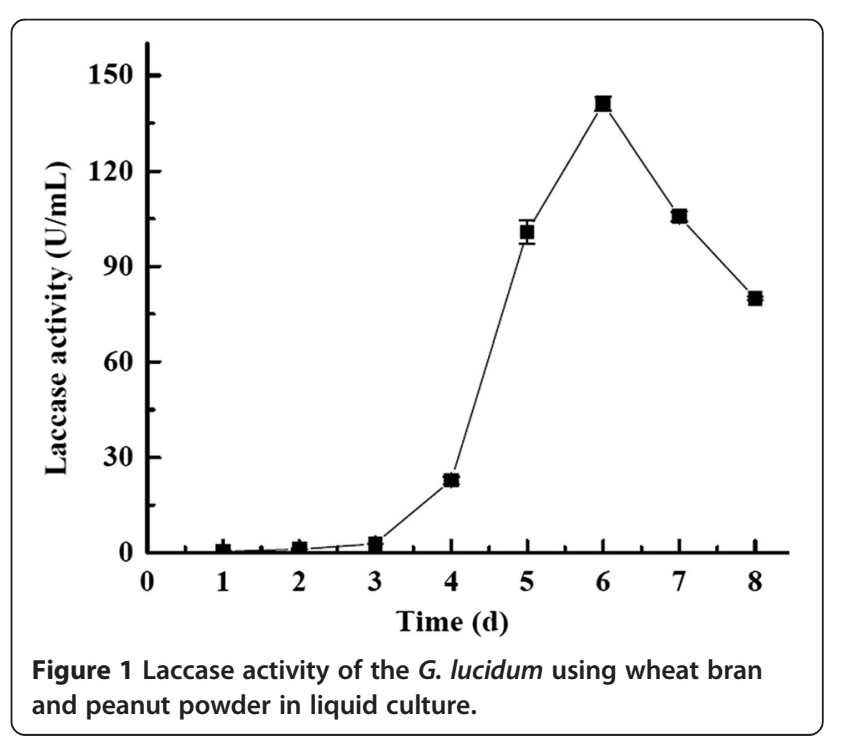


results, when induced by the mixture of tamarind shell, ethanol, $\mathrm{CuSO}_{4}$, and gallic acid, another G. lucidum strain produced four laccase isoenzymes [15]. Responsive elements that are found in various locations along the laccase promoter sequences may contribute to the variation in the laccase isoforms produced among $G$. lucidum strains. Several reports have highlighted their presence and postulated that these responsive elements, including metal-responsive element, xenobiotic response element, heat shock-responsive element, and antioxidant response element, may regulate laccase gene transcription, and their locations and orientations suggest a complex picture of laccase expression regulation [16]. On the other hand, the differential expression of laccase isoenzyme genes might also arise from different ecological origins of these mushrooms $[6,8]$.

\section{Laccase purification and characterization}

Laccase was purified from crude culture filtrate according to the methods described in the 'Methods' section. The summary of purification steps is presented in Table 1. One laccase was 14.19-fold purified from its initial culture broth with a final yield of 5.5\%. The purified laccase exhibited a single band both on native PAGE and sodium dodecyl sulfate (SDS)-PAGE (Figure 2), suggesting a homogenous form. The specific activity of the laccase was $186 \mathrm{U} / \mathrm{mg}$ when estimated with ABTS as the substrate.

G. lucidum contains 16 laccase genes in its genome [17]. Based on data-dependent liquid chromatography-electrospray ionization-tandem mass spectrometry (LC-ESI-MS/ MS), the purified laccase matched the laccases Glac6 and Glac15 (Additional file 1: Table S1 and Table S2) in the genome of G. lucidum Xiangnong No.1. Furthermore, its N-terminal sequence was GIGPTTDLTISNADI, completely matching the amino acidic sequence starting at position 22 of Glac15. However, G. lucidum 77002 is not the same strain compared to G. lucidum Xiangnong No.1, indicating that the purified protein may be Glac15, and suggested that a 21-amino acid signal peptide exists in the zymogen. As the protein obtained in this study showed the highest sequence identity with Glac15 from G. lucidum Xiangnong No.1, it was also designated as Glac15. To the best of our knowledge, this is the first report of Glac15 from G. lucidum [10-15,17-22]. Data bank homology searches (NCBI) further confirms the novelty of the purified Glac15 (Table 2) and returned a laccase from G. lucidum (GenBank: AHA83584) as the best hit (93\% identity), followed by another two laccases from G. lucidum (GenBank: ABK59822 and ABK59823) with 87\% identity. These three proteins were identified by whole genome sequencing and have not been characterized. When compared with the characterized laccases from G. lucidum, the N-terminal region of Glac15 shared the highest sequence homology of $93 \%$ with the laccase of KULac1, KULac3, KULac4, and KULac5 from Ganoderma sp. KUAlk4 [22] (Table 2).

\section{Effect of $\mathrm{pH}$ on Glac15 activity}

The $\mathrm{pH}$ profiles for fungal laccases toward phenolic substrates are usually narrow bell-shaped, with optimal $\mathrm{pH}$ around 5 , and little activity can be detected at neutral $\mathrm{pH}$ or above [23,24]. Similar to most fungal laccases, Glac15 could oxidize laccase-specific substrate syringaldazine at a $\mathrm{pH}$ range of 4.0 to 7.0 , with a $\mathrm{pH}$ optimum of 4.5 (Figure 3a). The pH optimum for Glac15 on oxidizing other phenol substrates such as 2,6-dimethoxyphenol (2,6-DMP), guaiacol, catechol, and L-dopamine
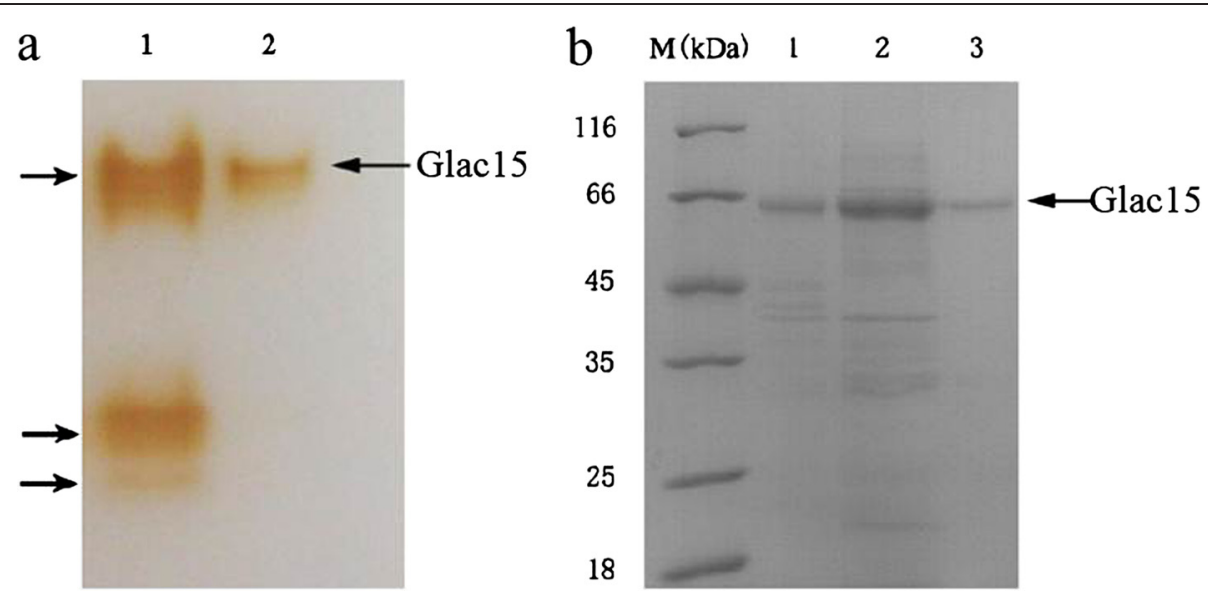

Figure 2 Native PAGE and SDS-PAGE of laccase purification. (a) Zymography of crude and purified laccase. Laccase activity was performed using $1 \mathrm{mM}$ guaiacol as substrate. Lanes: 1: crude laccase; 2: purified laccase. (b) SDS-PAGE of crude and purified laccase. Lanes: 1: crude protein extract produced by filtering the fermentation supernatant through six layers of sterile gauze; 2: crude protein extract after ultrafiltration; 3: purified Glac15 after DEAE-Sepharose FF chromatography. 
Table 1 Summary of the purification steps of extracellular laccase Glac15 from G. Iucidum 77002

\begin{tabular}{lllllll}
\hline Purification step & Total volume $(\mathbf{m l})$ & Total activity $(\mathbf{U})$ & Total Protein $(\mathbf{m g})$ & $\begin{array}{l}\text { Specific activity } \\
(\mathbf{U} / \mathbf{m g})\end{array}$ & Percent recovery (\%) & Purification fold \\
\hline Crude culture filtrate & 1,250 & 47,600 & 3,630 & 13.1 & 100.00 & 1.00 \\
Ultrafiltration & 100 & 28,000 & 1,100 & 25.5 & 58.8 & 1.94 \\
DEAE-Sepharose FF & 30 & 2,600 & 14 & 186 & 5.5 & 14.19 \\
\hline
\end{tabular}

were 4.5, 5.0, 5.0, and 4.5, respectively (Table 3 ). In contrast, for non-phenolic substrates, ABTS and $\mathrm{K}_{4} \mathrm{Fe}(\mathrm{CN})_{6}$, Glac15 has been observed to present monotonic activity profiles, in which the rate decreased as the $\mathrm{pH}$ increased from 2.5 to 7.0 , with the optimum $\mathrm{pH}$ being 2.5 (Table 3 ), like most fungal laccases [23]. The monotonic $\mathrm{pH}$ dependent decrease of the activity has been interpreted as the sole effect of hydroxyl ion inhibition [24]. On the other hand, Glac15 was highly stable at $\mathrm{pH}$ 5.0 to 7.0. After incubation at $50^{\circ} \mathrm{C}$ for $120 \mathrm{~min}$, Glac15 retained more than $70 \%$ of its original activities. In contrast, the enzyme was unstable at low $\mathrm{pH}$, with approximately $20 \%$ activity left after incubation at $\mathrm{pH} 4.0$ (Figure 3b) for $120 \mathrm{~min}$ at $50^{\circ} \mathrm{C}$. This is similar to most fungal laccases, which are functional at acidic and near neutral $\mathrm{pH}$ but lose their activities under alkaline conditions $[22,25]$.

\section{Effect of temperature on Glac15 activity}

Glac15 showed its maximal activity at $45^{\circ} \mathrm{C}$ toward syringaldazine and displayed more than $80 \%$ of the maximal activity at temperatures ranging from $35^{\circ} \mathrm{C}$ to $65^{\circ} \mathrm{C}$ for syringaldazine (Figure 3c). However, laccase from G. lucidum with the optimal temperature below $35^{\circ} \mathrm{C}$ has been described, for example, Ko et al. [18] reported a G. lucidum laccase showed the highest activity at $25^{\circ} \mathrm{C}$. The thermostability of fungal laccases varies considerably [23]. In contrast to a G. lucidum laccase, which was inactivated at $60^{\circ} \mathrm{C}$ [18], Glac15 was rather stable at temperatures lower than $55^{\circ} \mathrm{C}$, with about $90 \%$ activity retained after incubation at $\mathrm{pH} 5.0$ and $55^{\circ} \mathrm{C}$ for $2 \mathrm{~h}$ (Figure 3d). When incubated at $60^{\circ} \mathrm{C}$, Glac15 retained

Table 2 Overview of $\mathrm{N}$-terminal sequence of Glac15 to other laccases from $\mathbf{G}$. Iucidum

\begin{tabular}{lll}
\hline Protein & Sequence & Reference \\
\hline Lac15 & GIGPTTDLTISNADI & This study \\
GLac 1, 2, & GIGPT & {$[18]$} \\
- & GQNGDAVP & {$[19]$} \\
- & GIGPK & {$[20]$} \\
GLlac1 & GIGPK & {$[21]$} \\
KULac 2 & GIGPVADLTVRGGDI & {$[22]$} \\
KULac 1; 3; 4; 5 & GIGPVTDLTISNADI & {$[22]$} \\
Lac1 & GIGPTTDLTISNANI & AHA83584 \\
Lac4 & GIGPKTDLTISNADV & ABK59822/ABK59823 \\
\hline
\end{tabular}

$40 \%$ activity after $120 \mathrm{~min}$, with a half-life of $82 \mathrm{~min}$ (Figure 3d). Compared with other fungal laccases with high thermostability, Glac15 may be more suitable for several specific applications that run in moderate temperature, such as food and drink industries including ethanol production $[23,26]$.

\section{Substrate specificity}

Diverse substrates were oxidized by Glac15, and the kinetic parameters of the enzyme were calculated for each of them. As summarized in Table 3, ABTS and syringaldazine were the most reactive substrates for Glac15 in terms of affinity $\left(K_{\mathrm{m}}\right)$ and catalytic efficiency $\left(k_{\mathrm{cat}} / K_{\mathrm{m}}\right)$. The $K_{\mathrm{m}}$ values for ABTS and syringaldazine were in micromolar range. As most fungal laccases, these results confirm the specificity of ABTS and syringaldazine as non-phenolic and phenolic substrates, respectively, in laccase enzyme reaction. Glac15's substrates range was ranked as follows: ABTS $>$ syringaldazine $>2,6-\mathrm{DMP}>$ catechol $>$ guaiacol $>\mathrm{L}$-dopamine $>\mathrm{K}_{4} \mathrm{Fe}(\mathrm{CN})_{6}$. This is quite different from Tplac from Trametes pubescens, which showed a rank of ABTS $>2,6$-DMP $>$ L-dopa > guaiacol $>$ syringaldazine $>$ catechol [27]. Meanwhile, the $K_{\mathrm{m}}$ and $k_{\text {cat }} / K_{\mathrm{m}}$ values for ABTS were $19 \mu \mathrm{M}$ and $10.5 \mathrm{M}^{-1} / \mathrm{s}^{-1}$, respectively, higher than those of certain fungal laccases $[28,29]$.

\section{Effects of organic solvents, metal ions, and inhibitors on Glac15 activity}

Although there are several studies on characterization of laccases from G. lucidum, few of them reported the effects of organic solvents on the enzyme activity [10-15,17-22]. In order to obtain more information about the laccase from G. lucidum, ethanol, dichloromethane, ethyl ether, ethyl acetate, dimethyl sulfoxide (DMSO), acetaldehyde, and acetone were used to test the effects of organic solvents on Glac15 activity. All of the organic solvents tested inhibited protein activity, with about $80 \%$ of the original laccase activity was retained in the presence of $5 \%$ organic solvent $(v / v)$. This inhibitory effect of organic solvents increases as their concentration was increased (Figure 4). This is consistent with previous studies demonstrating that fungal laccases from Trametes versicolor [30] and Pleurotus ostreatus [31] were inactivated over $10 \%$ of the organic solvents. The instability of laccase in organic solvents may be attributed to the denaturation of the enzyme 

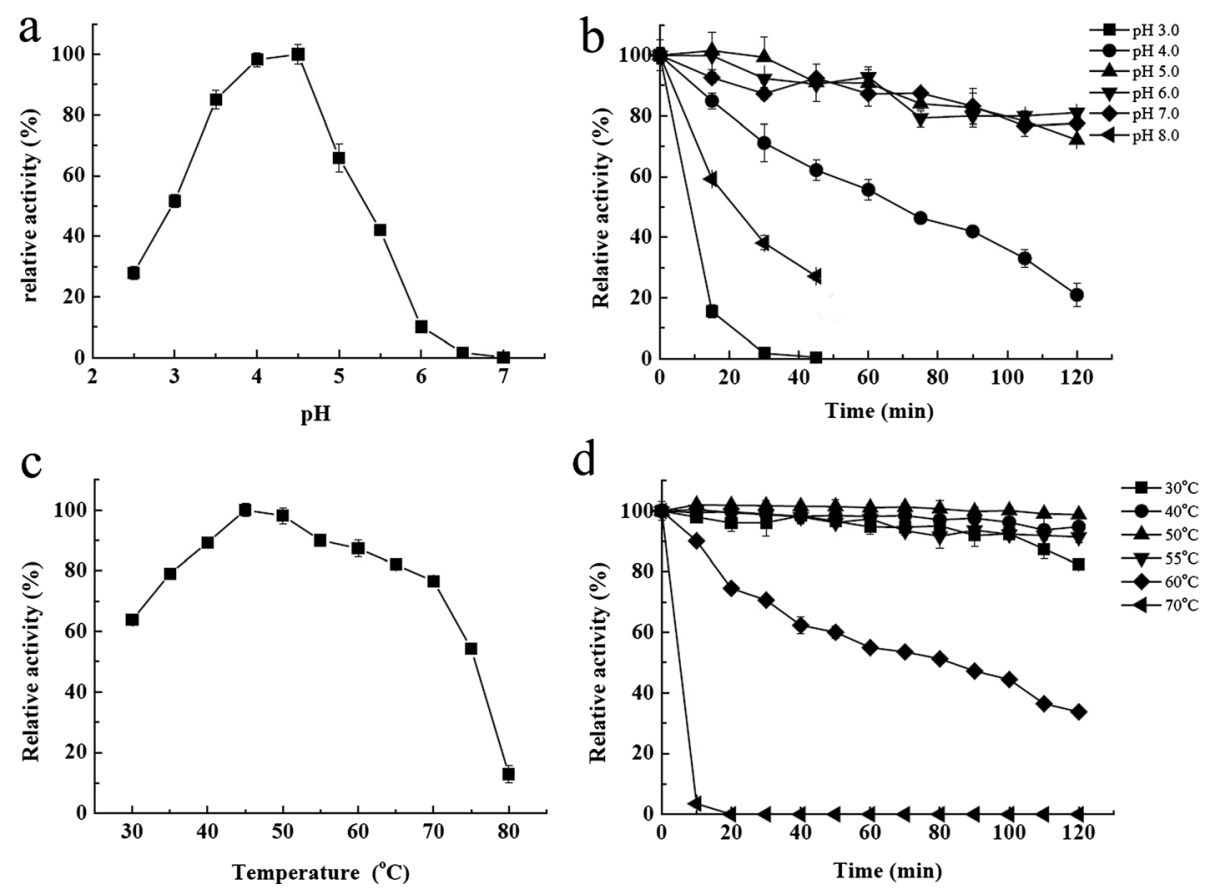

Figure 3 Effects of pH and temperature on the activity and stability of Glac15. (a) pH optimum, (b) pH stability, (c) temperature optimum, and (d) thermostability. Laccase activity was determined in $50 \mathrm{mM}$ citrate- $\mathrm{Na}_{2} \mathrm{HPO}_{4}$ buffer.

structure caused by interfering hydrophobic effects or the substitution of water molecules by the organic solvents at the active sites [30]. However, Glac15 retained about $60 \%$ of its original activity in the presence of $15 \%$ ethanol (Figure 4). Enzymatic reactions in compatible organic solvents such as ethanol allow access of laccase to some water-insoluble substrates, which may be helpful in the detoxification of many recalcitrant organic pollutants [32].

$\mathrm{Cu}^{2+}$ had negative effect on Glac15 activity (Figure 4). This is apparently different from bacterial laccases, as no activity was detected for the purified bacterial laccase but resumed by addition of $\mathrm{Cu}^{2+}$ [33]. Similar to $\mathrm{Cu}^{2+}$, $\mathrm{Ca}^{2+}$ also inhibited Glac15 activity. Two theories are proposed to explain the metal effects regarding laccase activity. One is that the binding of several metal ions, that is, $\mathrm{Cu}^{2+}$ or $\mathrm{Ca}^{2+}$, induces conformational modification of the enzyme and stimulates decomposition of the trimer complex containing substrate, enzyme, and metal ion, as evidenced by non-competitive inhibition model. The other is that the metal ion binds near the TI site of laccase and acts as a competitive inhibitor of electron donors by blocking the access of substrates to the TI site or inhibiting the electron transfer at the TI active site, thereby leading to inhibition of laccase activity [27,33]. Other cations such as $\mathrm{Mn}^{2+}, \mathrm{Li}^{+}, \mathrm{Zn}^{2+}$, and $\mathrm{K}^{+}$at a final concentration of $10 \mathrm{mM}$ did not have noticeable effects on Glac15 activity.

SDS is one of the anionic detergents known for its deleterious effect on the activity of most enzymes. In this study, SDS inhibited the activity, with complete inactivation (about 100\%) in $5 \mathrm{mM}$ SDS (Figure 4). According to Moore and Flurkey, the inhibition effect of SDS may be explained by the binding of small amounts of SDS on Glac15 which alters both its enzymatic and physical

Table 3 Substrate specificity of Glac15

\begin{tabular}{llllll}
\hline Substrate & Optimal $\mathbf{~ p H}$ & Optimal temp. $\left({ }^{\circ} \mathbf{C}\right)$ & $\boldsymbol{K}_{\mathbf{m}}(\mathbf{M})$ & $\boldsymbol{k}_{\text {cat }}\left(\mathbf{s}^{-\mathbf{1}}\right)$ & $\boldsymbol{k}_{\text {cat }} / \boldsymbol{K}_{\mathbf{m}}\left(\mathbf{M}^{-1} \mathbf{s}^{-1}\right)$ \\
\hline Syringaldazine & 4.5 & 45 & $6.2 \times 10^{-5}$ & $3.87 \times 10^{3}$ & $6.24 \times 10^{7}$ \\
2,6-DMP & 4.5 & 45 & $1.2 \times 10^{-4}$ & $7.44 \times 10^{2}$ & $6.20 \times 10^{6}$ \\
Guaiacol & 5.0 & 55 & $7.9 \times 10^{-4}$ & $1.70 \times 10^{3}$ & $2.15 \times 10^{6}$ \\
Catechol & 5.0 & 45 & $7.8 \times 10^{-4}$ & $5.48 \times 10^{3}$ & $7.03 \times 10^{6}$ \\
L-dopamine & 4.5 & 50 & $8.9 \times 10^{-4}$ & $2.95 \times 10^{3}$ & $3.31 \times 10^{6}$ \\
ABTS & 2.5 & 50 & $1.9 \times 10^{-5}$ & $2.00 \times 10^{2}$ & $1.05 \times 10^{7}$ \\
$\mathrm{~K}_{4} \mathrm{Fe}(\mathrm{CN})_{6}$ & 2.5 & 45 & $4.6 \times 10^{-3}$ & $2.71 \times 10^{4}$ & $5.89 \times 10^{6}$ \\
\hline
\end{tabular}




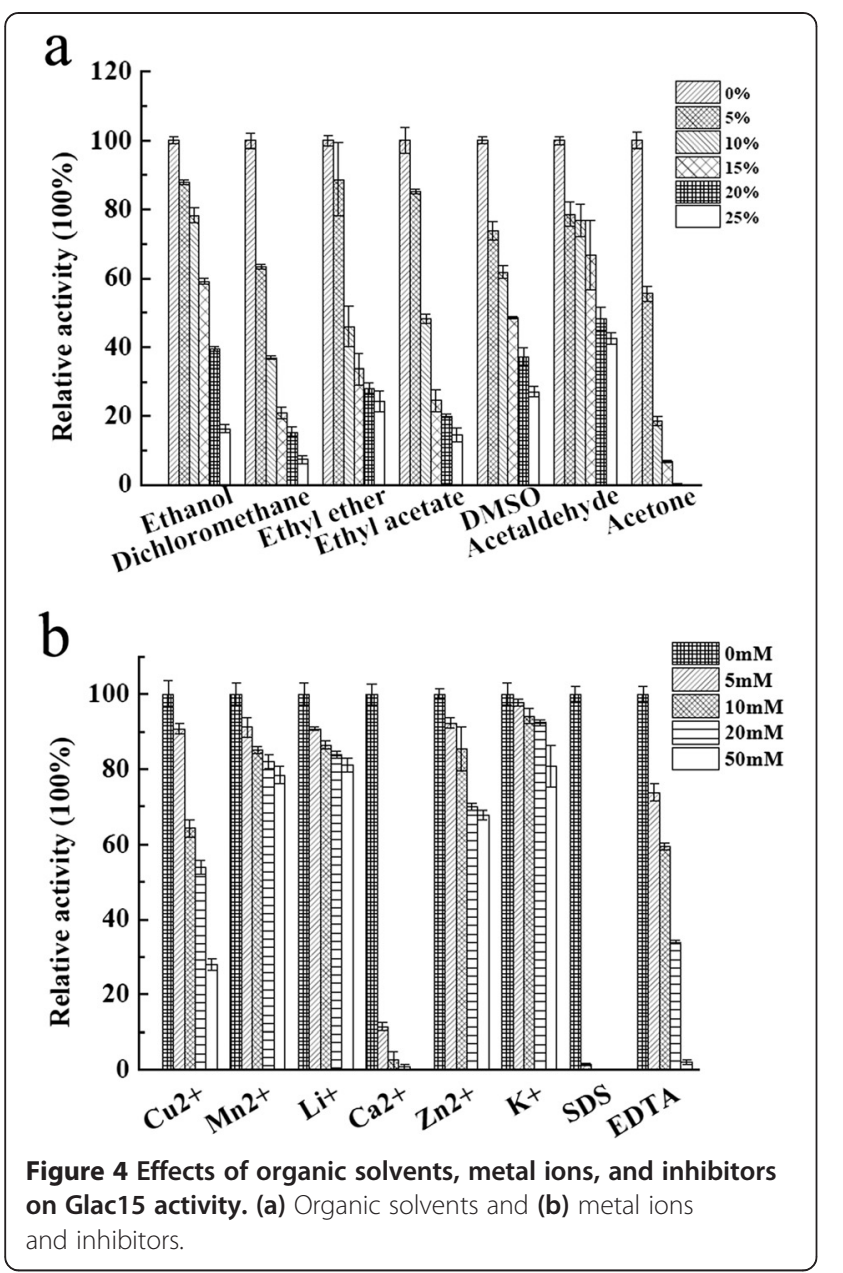

characteristics [34]. However, only partial inhibition (about 74\%) was observed for Glac15 in the presence of $5 \mathrm{mM}$ ethylenediaminetetraacetic acid (EDTA) (Figure 4), compared with complete inactivation observed for laccases from Thermus thermophilus [35] and Aspergillus ochraceus [36] in the presence of $1 \mathrm{mM}$ EDTA. Cabana et al. [37] have reported that the aggregation of laccase as cross-linked enzyme aggregates (CLEAs) improved its stability against EDTA by hindering access of EDTA to the $\mathrm{Cu}(\mathrm{II})$ ions of the protein. Thus, the resistance of Glac15 toward EDTA might be ascribed to the low accessibility of EDTA to the structural copper atoms of the protein.

\section{Laccase treatment of corn stover prehydrolysate}

After acidic steam pretreatment, the solid content and the prehydrolysate were separated. The pretreated solid content contained a total dry matter of $28.7 \%(w / w)$. Corn stover usually contains $33 \%$ to $40 \%$ cellulose, $13 \%$ to $31 \%$ hemicellulose, and $5 \%$ to $26 \%$ lignin [4]. As a consequence of hemicellulose solubilization, high xylose (11.39 g/L), arabinose $(1.37 \mathrm{~g} / \mathrm{L})$, and galactose $(1.35 \mathrm{~g} / \mathrm{L})$ were detected, and different degradation products were identified and quantified as soluble compounds in prehydrolysate. Among which, lignin, furfural, 5hydroxymethylfurfural (5-HMF), and acetic acid were formed at highest concentrations (Table 4). Furfural and 5-HMF are derived from pentoses especially xylose and hexose degradation, respectively, and acetic acid is formed by the hydrolysis of acetyl groups in hemicellulose [38]. In addition, phenolic compounds at a final concentration of $28.6 \mathrm{mM}$ were detected in the prehydrolysate. These compounds, derived from guaiacyl propane units and syringylpropane units present in lignin [39], are considered to be inhibitors and can affect biochemical pathways in the fermenting microorganisms and interact with cellulolytic enzymes, leading to reduced final ethanol titers and volumetric productivities [2-4].

Laccases have been applied in a few cases to remove specifically phenolic compounds in steam-exploded biomass [7]. However, little information of laccases from $G$. lucidum on removing phenolic compounds from steamexploded biomass has been observed [7,13]. Our results showed that Glac15 can function on the phenolic compounds derived from steam-exploded corn stover. When prehydrolysate $\mathrm{pH}$ was adjusted from 1.4 to $3.0,4.0$, and 5.0 in control samples, total phenolic compound contents decreased from 28.61 to $25.21,24.39$, and $23.38 \mathrm{mM}$, respectively, in the first $10 \mathrm{~min}$ and were not significantly changed even after $24 \mathrm{~h}$ incubation, suggesting that phenolic compounds during steam explosion are solubilized and stable at $\mathrm{pH} 1.4$ [5]. However, when $\mathrm{pH}$ was increased to 3.0 to 5.0 , acetic acid was transformed to acetate. This might lead to the polymerization of phenolic compounds. Addition of Glac15 removed about $60 \%, 78 \%$, and $84 \%$ of the phenolic compounds at $\mathrm{pH} 3.0, \mathrm{pH} 4.0$, and $\mathrm{pH} 5.0$, respectively, after $24 \mathrm{~h}$ treatment (Figure 5). As lignin derivates generated during pretreatment are phenolic compounds similar to guaiacol and syringaldazine, the increased reduction ability of Glac15 with increment of $\mathrm{pH}$ could be explained by the higher laccase activity observed with phenolic substrates at $\mathrm{pH} 4.5$ to 5.0 (Table 3). On the other hand, higher laccase doses $(0.05,0.1$, and $0.2 \mathrm{U} / \mathrm{mL})$ did not result in significantly higher detoxification (Figure 5). Increasing enzyme specificity for removing phenols allows decreasing enzymes doses. Therefore, low Glac15 concentrations are suitable for detoxification of steam-exploded corn stover, which is an important aspect for the application of enzymes in industrial applications [5].

Glac15-treated prehydrolysate was employed to test the effect of laccase treatment on yeast growth. When Saccharomyces cerevisiae CICC31014 strains were cultured in yeast nitrogen base (YNB) medium in the presence of $25 \%, 50 \%$, and $75 \%$ prehydrolysate (the final 
Table 4 Composition of pretreated corn stover and prehydrolysate

\begin{tabular}{|c|c|c|c|c|c|}
\hline \multicolumn{2}{|l|}{ Corn stover } & \multicolumn{4}{|l|}{ Prehydrolysate } \\
\hline Component & $\%$ weight & Monosaccharides & Concentration $(g / L)$ & Inhibitors & Concentration \\
\hline Cellulose & 23.15 & Glucose & 5.74 & Furfural & $2.28 \mathrm{~g} / \mathrm{L}$ \\
\hline Hemicellulose & 13.44 & Xylose & 11.39 & 5-HMF & $0.33 \mathrm{~g} / \mathrm{L}$ \\
\hline Lignin & 10.92 & Arabinose & 1.37 & Acetic acid & $0.309 \mathrm{~g} / \mathrm{L}$ \\
\hline Extracts & 34.50 & Galactose & 1.35 & Formic acid & $0.045 \mathrm{~g} / \mathrm{L}$ \\
\hline \multirow[t]{2}{*}{ Unknown compounds } & 17.99 & & & Lignin & $4.9 \mathrm{~g} / \mathrm{L}$ \\
\hline & & & & Total phenol & $28.6 \mathrm{mM}$ \\
\hline
\end{tabular}

glucose concentration was 21.44, 22.87, and $24.31 \mathrm{~g} / \mathrm{L}$, respectively), strains showed no growth in all of the untreated samples (Figure 6). In contrast, after treatment with laccase, yeast cell growth improved considerably. The biomass reached $5.55 \pm 0.27,9.33 \pm 0.32$, and $11.81 \pm 0.33$ (optimal density at $600 \mathrm{~nm}\left(\mathrm{OD}_{600}\right)$ ) in the samples containing $25 \%, 50 \%$, and $75 \%$ prehydrolysates, respectively. In accordance with Moreno et al. [40], who reported the treatment of slurry with laccase increased the yeast cell viability, our results also showed the increased cell viability, evidenced the detoxication effect of Glac15 on prehydrolysate. The higher cell density could be attributed to the higher concentration of glucose added to the medium with the addition of prehydrolysates. On the other hand, the higher the concentration of prehydrolysate, the higher the concentrations of other inhibitors such as furan derivates and weak acids. As a result, yeast growth in the former two samples had a shorter lag period (12 h) than that in the last sample (37 h) (Figure 6).

\section{Effects of laccase treatment on enzymatic hydrolysis and ethanol fermentation}

The effect of laccase treatment on enzymatic hydrolysis was evaluated. After treating the solid fraction with Glac15, the glucose recovery was not apparently changed when checked by a statistical analysis (Figure 7, Table S2).
This is different from the previous studies reported by Tabka et al. [41] and Jurado et al. [5], who described a lower glucose recovery after enzymatic hydrolysis of steam-exploded wheat straw treated with laccase. The lower recovery was explained by the release of certain phenolic compounds by laccases inhibiting cellulolytic enzymes $[5,41,42]$. Based on our results, cellobiose was increased from $2.41 \pm 0.17$ to $3.25 \pm 0.21 \mathrm{~g} / \mathrm{L}$ after treating with Glac15, indicating that cellobiose was accumulated during the process. On the contrary, improved glucose recovery by laccase treatment of steam-exploded softwood has been reported, and a decrease in the unproductive binding of cellulases to lignin after laccase treatment has been suggested [43]. With the addition of prehydrolysate, cellulase activities may have been inhibited, as there was no increase in glucose concentration after addition of prehydrolysate. Statistical analysis showed that the glucose and cellulase recoveries were not significantly changed even after treating with Glac15 $(P>0.05)$, indicating that Glac15 had no effect on saccharification in the presence of prehydrolysate.

From an economical and environmental point of view, the use of prehydrolysate can increase the fermentable sugar concentration, decrease both operational costs and wastewater, and obtain a higher ethanol production $[42,44,45]$. As a result, four groups containing only solid content $(5 \%, m / v)$, solid content $(5 \%, m / v)$ and treated

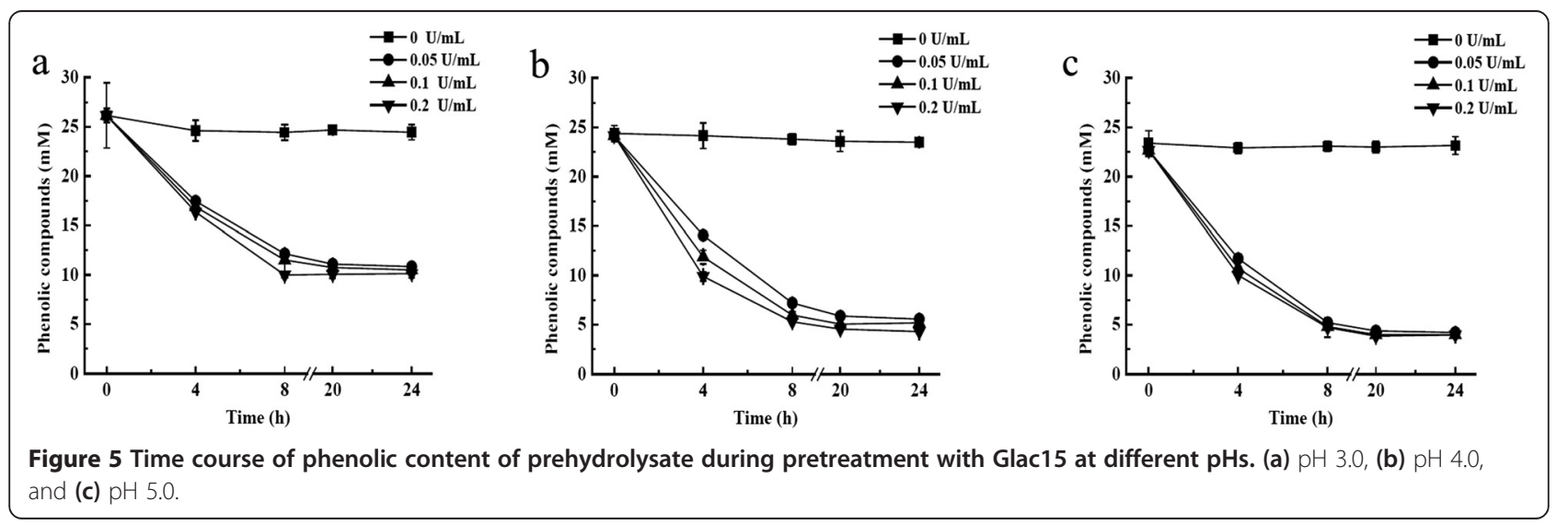




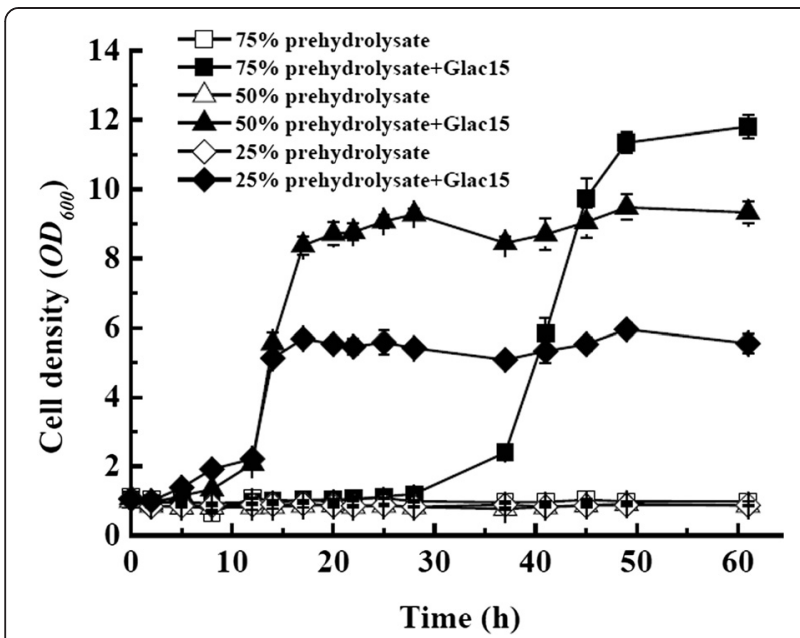

Figure 6 Time course of yeast growth in the presence of different concentrations of prehydrolysate treated or not with Glac15.

with Glac15, solid content $(5 \%, \mathrm{~m} / \mathrm{v})$ containing $50 \%$ prehydrolysate, and solid content $(5 \%, \mathrm{~m} / \mathrm{v})$ containing $50 \%$ prehydrolysate treated with Glac15 were employed to evaluate the effect of laccase treatment on ethanol fermentation. Fermentation was improved after detoxification with Glac15. After $60 \mathrm{~h}$ fermentation with $S$. cerevisiae, results showed that sugar consumption and ethanol yield were higher in samples treated with laccases than in control samples (Figure 7). The final ethanol concentrations of three groups were $9.74 \pm 0.18$, $10.05 \pm 0.15,10.11 \pm 0.21$, and $10.81 \pm 0.23 \mathrm{~g} / \mathrm{L}$, respectively (Figure 7c). Laccase treatment to increase ethanol production has been reported by others. For example, Jonsson et al. [46] reported that ethanol productivity was increased by two to three times when treated a willow hemicellulose hydrolysate from willow with laccase and lignin peroxidase from the white-rot basidiomycete fungus $T$. versicolor. When laccase was used to detoxify water-impregnated wheat straw or acid-impregnated wheat straw, ethanol yield was two times higher than the control that has not been treated with laccase [5]. Compared to these results, an increasement of about $10 \%$ ethanol was obtained when treated with Glac15. To maximize the improvement of ethanol production caused by laccase treatment, further researches on decreasing the quantity of cellulases enzymes in enzymatic hydrolysis assays to lower activities, or increasing solid fraction consistency, are to be performed.

\section{Conclusions}

In this study, G. lucidum 77002 produces $141.1 \pm 0.2 \mathrm{U} / \mathrm{mL}$ laccase activity within 6 days when using wheat bran and peanut powder as energy sources in liquid culture medium. A new isoenzyme named Glac15 was identified, purified, and characterized. It showed high activity toward phenolic and non-phenolic substrates syringaldazine and ABTS. When used in bioethanol production process, low amount Glac15 removed $84 \%$ of the phenolic compounds in prehydrolysate at $\mathrm{pH} 5$ and considerably improved yeast growth. Addition of Glac15 before cellulase hydrolysis improved $10 \%$ ethanol yield. Our results showed that the G. lucidum laccase Glac15 has potentials in bioethanol production industry.

\section{Methods}

Chemicals, strains, media, and culture conditions

Filamentous fungus G. lucidum 77002 was preserved at culture collection of the School of Life Sciences, Anhui University, China (China Center for Type Culture Collection No. AF2013025). S. cerevisiae was from China Center of Industrial Culture Collection, Beijing, China (No. CICC31014). Syringaldazine, 2,6-DMP, guaiacol, catechol, L-dopamine, ABTS, and $\mathrm{K}_{4} \mathrm{Fe}(\mathrm{CN})_{6}$ were purchased from Sigma-Aldrich (St. Louis, MO, USA). Wheat bran was from Zhangyuan (Bozhou, China), and peanut powder was purchased from Huiyou (Hefei, China).

G. lucidum 77002 was maintained on potato dextrose agar (PDA, contained 20.0 g glucose, $1.0 \mathrm{~g} \mathrm{KH}_{2} \mathrm{PO}_{4}, 1.5 \mathrm{~g}$ $\mathrm{MgSO}_{4} \cdot 7 \mathrm{H}_{2} \mathrm{O}, 50.0 \mu \mathrm{g}$ vitamin $\mathrm{B}_{1}, 15.0 \mathrm{~g}$ agar powder, and $200.0 \mathrm{~g}$ potato extract liquid/L) slants at $4^{\circ} \mathrm{C}$. YMG
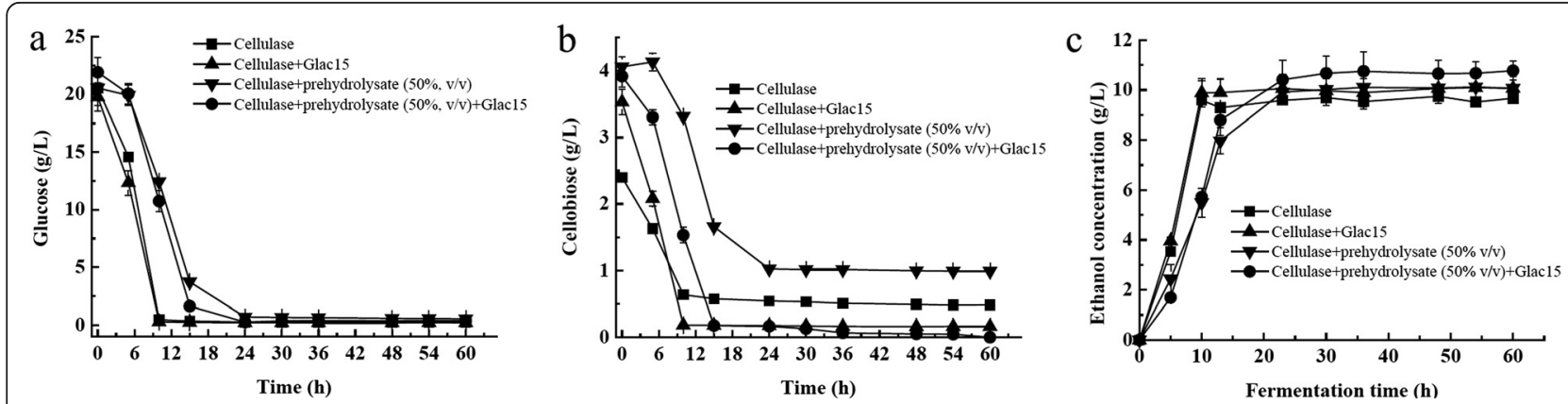

Figure 7 Time course of sugar consumption and ethanol yield using solid fraction and solid fraction with prehydrolysate $(50 \%$, $v / v)$ treated or not with Glac15. (a) Glucose. (b) Cellobiose. (c) Ethanol concentration. 
liquid medium (contained $10.0 \mathrm{~g}$ malt extract, $4.0 \mathrm{~g}$ yeast extract, and 10.0 g glucose/L) was used to prepare $G$. lucidum 77002 inoculation. The liquid fermentation medium used for producing laccase contained $30.0 \mathrm{~g}$ peanut powder, $30.0 \mathrm{~g}$ wheat bran, and $1.5 \mathrm{~g} \mathrm{KH}_{2} \mathrm{PO}_{4} / \mathrm{L}$. YNB medium (contained $1.7 \mathrm{~g}$ yeast nitrogen base, $5.0 \mathrm{~g}$ ammonia sulfate, and $20.0 \mathrm{~g}$ glucose/L) was used for culture of S. cerevisiae.

\section{Laccase production in liquid culture}

When producing laccases, four to five plugs (diameter in $5 \mathrm{~mm}$ ) of G. lucidum 77002 actively grown on PDA plates were used to inoculate 250-mL Erlenmeyer flasks containing $100 \mathrm{~mL}$ YMG medium. The culture was incubated at $28^{\circ} \mathrm{C}$ on a rotary shaker at $120 \mathrm{rpm}$. A 4-dayold liquid culture was homogenized with a sterile blender at 3,000 rpm for $10 \mathrm{~s}$, and a volume of $5 \mathrm{~mL}$ was inoculated into the new $400 \mathrm{~mL}$ (in 1-L Erlenmeyer flasks) liquid fermentation medium and was cultivated under the same conditions for 8 days.

\section{Laccase purification}

Unless otherwise stated, all procedures were performed at $4{ }^{\circ} \mathrm{C}$. The culture fluid was first filtered through six layers of sterile gauze and washed with three volumes of citrate-phosphate buffer (50 mM, pH 5.0). The aqueous solution $(1.25$ L) was centrifuged at $10,000 \times g$ for $10 \mathrm{~min}$ and then concentrated to $100 \mathrm{~mL}$ in a Minitan Ultrafiltration System (Millipore, Bedford, MA, USA) with a low-binding regenerated cellulose membrane (Millipore, Bedford, MA, USA). The concentrate was centrifuged at $12,000 \times g$ for $20 \mathrm{~min}$ to discard the sediment generated during the ultrafiltration, and the supernatant was then dialyzed against buffer A ( $20 \mathrm{mM}$ citratephosphate, $\mathrm{pH}$ 7.5) overnight followed by centrifugation as before. The supernatant was applied to a DEAE-Sepharose FF column $(10 \times 200 \mathrm{~mm}$, Amersham Pharmacia, Uppsala, Sweden) preequilibrated with buffer A. The column was then washed with approximately $100 \mathrm{~mL}$ buffer A to remove melanin and polysaccharide and eluted with a linear gradient of $\left(\mathrm{NH}_{4}\right)_{2} \mathrm{SO}_{4}$ (0 to $1 \mathrm{M}$ in buffer $\mathrm{A}$; flow rate $0.8 \mathrm{~mL} / \mathrm{min}$ ). The fractions containing laccase were pooled and dialyzed against $50 \mathrm{mM}$ citrate- $\mathrm{Na}_{2} \mathrm{HPO}_{4}$ buffer $(\mathrm{pH} 7.5)$ and stored at $4^{\circ} \mathrm{C}$.

\section{Laccase identification}

The purified laccase was identified according to Rühl et al. [47] with slight modifications. Briefly, the purified protein was recovered for SDS-PAGE [48]. Coomassie brilliant blue R-250-stained protein bands were cut with a razor blade. The gel pieces were digested with trypsin and analyzed by LC-ESI-MS/MS (LTQ, Thermo Fisher Scientific, Shanghai, China). Proteins were then identified by searching the data against a database of the G. lucidum
Xiangnong No.1 genome [17]. To further confirm the identity of protein, purified laccase was electro-blotted directly from the SDS-PAGE gel onto a polyvinylidene difluoride membrane (Sequi-Blot PVDF, Bio-Rad, Hercules, CA, USA) and located by Coomassie blue R-250 staining. The band on the PVDF membrane corresponding to the Glac15 was excised and subjected to Edman degradation. $\mathrm{N}$-terminal sequences of the proteins were determined using a PPSQ-33A Edman degradation unit (Shimadzu, Kyoto, Japan) and the data was processed by PPSQ-30 Data Processing software.

\section{Enzyme assay}

The assay mixture consisted of $10 \mu \mathrm{L}$ of appropriately diluted laccase stock and $990 \mu \mathrm{L}$ of $50 \mathrm{mM}$ citratephosphate buffer ( $\mathrm{pH} 4.0$ ) containing $0.5 \mathrm{mM}$ ABTS $\left(\varepsilon_{420}=36,000 \mathrm{M}^{-1} \mathrm{~cm}^{-1}\right)$ [49]. The reaction was initiated by adding enzyme into the solution. After incubation at $50^{\circ} \mathrm{C}$ for $3 \mathrm{~min}$, the absorbance was immediately measured at $420 \mathrm{~nm}$. Alternative substrates for the measurement of laccase activity were $100 \mu \mathrm{M}$ syringaldazine $\left(\varepsilon_{525}=\right.$ $\left.65,000 \mathrm{M}^{-1} \mathrm{~cm}^{-1}\right)$ [50], $2 \mathrm{mM}$ 2,6-DMP $\left(\varepsilon_{468}=49,600 \mathrm{M}^{-}\right.$ $\left.{ }^{1} \mathrm{~cm}^{-1}\right)$ [51], $2 \mathrm{mM}$ guaiacol $\left(\varepsilon_{465}=12,000 \mathrm{M}^{-1} \mathrm{~cm}^{-1}\right)$ [52], $2 \mathrm{mM}$ catechol $\left(\varepsilon_{388}=1,300 \mathrm{M}^{-1} \mathrm{~cm}^{-1}\right)$ [51], $2 \mathrm{mM}$ L-dopamine $\left(\varepsilon_{475}=2,835 \mathrm{M}^{-1} \mathrm{~cm}^{-1}\right)$ [53], and $2 \mathrm{mM} \mathrm{K}_{4} \mathrm{Fe}(\mathrm{CN})_{6}$ $\left(\varepsilon_{405}=900 \mathrm{M}^{-1} \mathrm{~cm}^{-1}\right)$ [54], respectively. Reactions with heat-treated laccase were used as the controls. One activity unit (U) was defined as the amount of enzyme required for oxidizing $1 \mu \mathrm{mol}$ of substrate/min [33].

\section{Laccase characterization}

The effect of $\mathrm{pH}$ on laccase activity was examined in the $\mathrm{pH}$ range of 2.5 to 7.0 at $50^{\circ} \mathrm{C}$ in $50 \mathrm{mM}$ citratephosphate buffer. The enzyme stability against $\mathrm{pH}$ was determined by measuring the residual laccase activities after incubation at $50^{\circ} \mathrm{C}$ in the aforementioned buffers, and residual activities were determined every $15 \mathrm{~min}$. The effect of temperature on the activity was measured by incubating protein at optimal $\mathrm{pH}$ and a temperature range of $30^{\circ} \mathrm{C}$ to $80^{\circ} \mathrm{C}$ in an interval of $5^{\circ} \mathrm{C}$. Thermostability was determined by incubating protein at various temperatures $\left(30^{\circ} \mathrm{C}\right.$ to $\left.70^{\circ} \mathrm{C}\right)$ at $\mathrm{pH} 5.0$, and residual activities were determined every $10 \mathrm{~min}$.

The effects of metal ions $\left(\mathrm{Cu}^{2+}, \mathrm{Mn}^{2+}, \mathrm{Li}^{+}, \mathrm{Ca}^{2+}, \mathrm{Zn}^{2+}\right.$, $\mathrm{K}^{+}$, using sulfate as the donor, 0 to $50 \mathrm{mM}$ ), SDS (0 to $50 \mathrm{mM}$ ), EDTA (0 to $50 \mathrm{mM}$ ), and organic solvents (ethanol, dichloromethane, ethyl ether, ethyl acetate, DMSO, acetaldehyde, and acetone, 0 to $25 \%, v / v$ ) on the enzyme activity were investigated by adding different concentrations of each effector into the reaction system when addition of substrate ABTS. The enzymatic assays were conducted under the conditions described in enzyme assay. 


\section{Enzyme kinetics}

The kinetics and the specificity of Glac15 toward each of these substrates were measured at the optimum $\mathrm{pH}$ of the enzyme (Table 3). The Michaelis-Menten and catalytic constants $\left(K \mathrm{~m}, k_{\text {cat }}\right.$, and $\left.k_{\text {cat }} / K \mathrm{~m}\right)$ were determined by incubating Glac15 with various concentrations of syringaldazine, 2,6-DMP, guaiacol, catechol, L-dopamine, ABTS, and $\mathrm{K}_{4} \mathrm{Fe}(\mathrm{CN})_{6}$. The values for the kinetic parameters and their corresponding errors were then calculated.

\section{Corn stover pretreatment}

Corn stover was used as raw material. It was milled using a laboratory hammer mill, in order to obtain a chip size round $2 \mathrm{~mm}$, and stored at room temperature until use. Milled biomass was pretreated by steam explosion with a raw material: $\mathrm{H}_{2} \mathrm{O}$ proportion of 1:10 $(w / v)$ and in the presence of $0.8 \% \mathrm{H}_{2} \mathrm{SO}_{4}(v / v)$ in a $10-\mathrm{L}$ reactor at $160^{\circ} \mathrm{C}$ for $30 \mathrm{~min}$. After steam explosion treatment, the whole slurry was filtered with the aim of obtaining a liquid fraction and a solid fraction.

\section{Laccase treatment of the prehydrolysate}

The effect of laccase treatment on phenolic compounds in corn stover prehydrolysate was evaluated using the liquid fraction obtained from pretreatment. Before adding Glac15, prehydrolysate was adjusted to $\mathrm{pH} 3.0$ to $\mathrm{pH} 5.0$ and kept for $1 \mathrm{~h}$ and then incubated with $0.05,0.1$, or $0.2 \mathrm{U} / \mathrm{mL}$ of purified Glac15 for $24 \mathrm{~h}$ at $45^{\circ} \mathrm{C}$ in a rotary shaker (200 rpm) [5]. Samples were periodically taken and the supernatants analyzed for total phenols as described below. To evaluate the effect of laccase treatment on yeast growth, prehydrolysates were diluted to $75 \%, 50 \%$, and $25 \%$ of original concentration by $4 \times$ YNB medium (the final concentration of YNB medium was $1 \times$ ) [55]. After treatment with $0.05 \mathrm{U} / \mathrm{mL}$ Glac15 at pH 5.0 and $45^{\circ} \mathrm{C}$ for $8 \mathrm{~h}$, S. cerevisiae in a final concentration of $1 \mathrm{OD}_{600}$ were inoculated and were incubated at $30^{\circ} \mathrm{C}$ in a rotary shaker $(200 \mathrm{rpm})$ for $60 \mathrm{~h}$. In all cases, control assays were performed under the same conditions but without addition of laccase Glac15. All the experiments were carried out in triplicate.

\section{Laccase treatment and enzymatic hydrolysis of thermochemical pretreated corn stover}

Laccase treatment on pretreated solid fraction was performed as follows: in the first set of experiments, a total volume of $40 \mathrm{~mL}$ containing $2.0 \mathrm{~g}$ (dry weight, $5 \% \mathrm{w} / v)$ pretreated solid fraction, $2.0 \mathrm{~g} / \mathrm{L}\left(\mathrm{NH}_{4}\right)_{2} \mathrm{SO}_{4}$, $4.0 \mathrm{~g} / \mathrm{L} \mathrm{KH}_{2} \mathrm{PO}_{4}, 1.0 \mathrm{~g} / \mathrm{L} \mathrm{MgSO}_{4}$, and $0.2 \mathrm{~g} / \mathrm{L} \mathrm{CaCl}_{2}$ was used; in the second set of experiments, $5 \%$ solid fraction and $50 \%$ prehydrolysate $(v / v)$ were added into the medium described above (the total volume was also $40 \mathrm{~mL}$ ). Depending on the previous experiments, an enzyme loading of $0.05 \mathrm{U} / \mathrm{mL}$ of Glac15 was added and then incubated at $45^{\circ} \mathrm{C}$ and $\mathrm{pH} 5.0$ in a rotary shaker $(200 \mathrm{rpm})$. Control assay was performed under the same condition without addition of laccase. All experiments were carried out in triplicate. After $8 \mathrm{~h}$ of treatment, another 24-h enzymatic hydrolysis at $45^{\circ} \mathrm{C}$ was performed following the addition of 30 FPU/g (dry weight) cellulase (Sunson Biotech., Peking, China). Then the temperatures of hydrolyzed samples were reduced to $30^{\circ} \mathrm{C}$ and $S$. cerevisiae in a final concentration of $1.0 \mathrm{OD}_{600}$ was aseptically inoculated. The fermentation was performed at $30^{\circ} \mathrm{C}$ in a rotary shaker $(200 \mathrm{rpm})$ for another $60 \mathrm{~h}$. Samples of different time points were recovered and centrifuged at $15,000 \times g$ for $5 \mathrm{~min}$; the supernatants were filtered through a $0.22-\mu \mathrm{m}$ Millipore filter (Millipore, Bedford, MA, USA) and analyzed for glucose consumption and ethanol concentration.

\section{Analytical methods}

Biomass was determined using absorbance at $600 \mathrm{~nm}$. The ethanol concentration was determined using an HPLC system according to Ji et al. [55]. Xylose, arabinose, galactose, furfural, 5-HMF, formic acid, and acetic acid concentrations were measured according to Moreno et al. [42]. Total phenols were measured according to Folin-Ciocalteu method using vanillin as a standard [56]. The data presented are the average values from triplicate technical repeats of measurements.

\section{Additional file}

Additional file 1: Tables S1 and S2 Table S1: Laccase peptides detected by LC-ESI-MS/MS and database search. Table S2: Sugar and ethanol concentrations after treated in different ways.

\section{Abbreviations}

2,6-DMP: 2,6-dimethoxyphenol; 5-HMF: 5-hydroxymethylfurfural; ABTS: 2,2'azino-bis-(3-ethylbenzothiazoline-6-sulfonic acid); DMSO: dimethyl sulfoxide; EDTA: ethylenediaminetetraacetic acid; $\mathrm{OD}_{600}$ : optimal density at $600 \mathrm{~nm}$; PAGE: polyacrylamide gel electrophoresis; PDA: potato dextrose agar; SDS: sodium dodecyl sulfate.

\section{Competing interests}

The authors declare that they have no competing interests.

\section{Authors' contributions}

$Z F, X L, X B$, and $Y X$ conceived and designed the experiments. $Z F, X L, L C$, and $Y S$ performed the experiments. $Z F, Y S, X Z, W F, X W$, and $Y X$ analyzed the data. $Z F, X B$, and $Y X$ contributed reagents/materials/analysis tools. $Z F, X Z$, $W X, B X$, and $Y X$ contributed to the writing of the manuscript. All authors have read and approved of the final version of the manuscript.

\section{Acknowledgements}

This work was supported by the Scientific Research Foundation for Returned Scholars, Ministry of Education of China (to YX), the Natural Science Foundation of the Department of Education of Anhui Province (KJ2013A022 to ZF), the Introduction Project of Academic and Technology Leaders in Anhui University (32030066 to ZF), and the Innovative Research Team Program of 211 Project in Anhui University. 


\section{Author details}

'School of Life Sciences, Anhui University, 111 Jiulong Road, Hefei, Anhui 230601, China. ${ }^{2}$ Anhui Provincial Engineering Technology Research Center of Microorganisms and Biocatalysis, 111 Jiulong Road, Hefei, Anhui 230601, China. ${ }^{3}$ The State Key Laboratory of Microbial Technology, School of Life Sciences, Shandong University, 27 Shanda Nanlu, Jinan, Shandong 250100, China. ${ }^{4}$ Department of Chemistry \& Biochemistry, Florida International University, Miami, FL 33199, USA.

\section{Received: 21 November 2014 Accepted: 9 March 2015}

\section{Published online: 31 March 2015}

\section{References}

1. Naik SN, Goud W, Rout PK, Dalai AK. Production of first and second generation biofuels: a comprehensive review. Renew Sust Energ Rev. 2010;14:578-97.

2. Jönsson L, Alriksson B, Nilvebrant N-O. Bioconversion of lignocellulose: inhibitors and detoxification. Biotechnol Biofuels. 2013;6:16.

3. Parawira W, Tekere M. Biotechnological strategies to overcome inhibitors in lignocellulose hydrolysates for ethanol production: review. Crit Rev Biotechnol. 2011;31:20-31.

4. Schroyen $\mathrm{M}$, Vervaeren $\mathrm{H}$, Van Hulle SWH, Raes K. Impact of enzymatic pretreatment on corn stover degradation and biogas production. Bioresour Technol. 2014:173:59-66.

5. Jurado M, Prieto A, Martínez-Alcalá Á, Martínez ÁT, Martínez MJ. Laccase detoxification of steam-exploded wheat straw for second generation bioethanol. Bioresour Technol. 2009;100:6378-84.

6. Hoegger PJ, Kilaru S, James TY, Thacker JR, Kües U. Phylogenetic comparison and classification of laccase and related multicopper oxidase protein sequences. FEBS J. 2006;273:2308-26.

7. Kudanga T, Roes-Hill ML. Laccase applications in biofuels production: current status and future prospects. Appl Microbiol Biotechnol. 2014;98:6525-42.

8. Zhou XW, Cong WR, Su KQ, Zhang YM. Ligninolytic enzymes from Ganoderma spp: current status and potential applications. Crit Rev Microbiol. 2013:39:416-26.

9. Chen S, Xu J, Liu C, Zhu Y, Nelson DR, Zhou S, et al. Genome sequence of the model medicinal mushroom Ganoderma lucidum. Nat Commun. 2012;3:913.

10. D'souza TM, Merritt CS, Reddy CA. Lignin-modifying enzymes of the white rot basidiomycete Ganoderma lucidum. Appl Environ Microbiol. 1999:65:5307-13.

11. de Souza Silva CMM, De Melo IS, De Oliveira PR. Ligninolytic enzyme production by Ganoderma spp. Enzyme Microb Technol. 2005;37:324-9.

12. Sharma KK, Shrivastava B, Sastry VRB, Sehgal N, Kuhad RC. Middle-redox potential laccase from Ganoderma sp.: its application in improvement of feed for monogastric animals. Sci Rep. 2013;3:1299.

13. Sitarz AK, Mikkelsen JD, Højrup P, Meyer AS. Identification of a laccase from Ganoderma lucidum CBS 229.93 having potential for enhancing cellulase catalyzed lignocellulose degradation. Enzyme Microb Technol. 2013;53:378-85.

14. Songulashvili G, Elisashvili V, Wasser SP, Nevo E, Hadar Y. Basidiomycetes laccase and manganese peroxidase activity in submerged fermentation of food industry wastes. Enzyme Microb Tech. 2007;41:57-61.

15. Manavalan T, Manavalan A, Thangavelu KP, Heese K. Characterization of optimized production, purification and application of laccase from Ganoderma lucidum. Biochem Eng J. 2013;70:106-14.

16. Piscitelli A, Giardina P, Lettera V, Pezzella C, Sannia G, Faraco V. Induction and transcriptional regulation of laccases in fungi. Curr Genomics. 2011:12:104-12

17. Liu D, Gong J, Dai W, Kang X, Huang Z, Zhang HM, et al. The genome of Ganoderma lucidum provide insights into triterpenes biosynthesis and wood degradation. Plos One. 2012;7:e36146

18. Ko EM, Leem YE, Choi HT. Purification and characterization of laccase isozymes from the white-rot basidiomycete Ganoderma lucidum. Appl Microbiol Biotechnol. 2001:57:98-102.

19. Wang $H X, N g$ TB. A laccase from the medicinal mushroom Ganoderma lucidum. Appl Microbiol Biotechnol. 2006;72:508-13.

20. You LF, Liu ZM, Lin JF, Guo LQ, Huang XL, Yang HX. Molecular cloning of a laccase gene from Ganoderma lucidum and heterologous expression in Pichia pastoris. J Basic Microbiol. 2013;53:1-8.
21. Joo SS, Ryu IW, Park JK, Yoo YM, Lee DH, Hwang KW, et al. Molecular cloning and expression of a laccase from Ganoderma lucidum, and its antioxidative properties. Mol Cells. 2008;25:7-11.

22. Teerapatsakul C, Abe N, Bucke C, Kongkathip N, Jareonkitmongkol S, Chitradon L. Novel laccases of Ganoderma sp. KU-Alk4, regulated by different glucose concentration in alkaline media. World J Microbiol Biotechnol. 2007;23:1559-67.

23. Baldrian P. Fungal laccases - occurrence and properties. FEMS Microbio Rev. 2006;30:215-42.

24. Xu F. Effects of redox potential and hydroxide inhibition on the $\mathrm{pH}$ activity profile of fungal laccases. J Biol Chem. 1997;272:924-8.

25. Sharma P, Goel R, Capalash N. Bacterial laccases. World J Microb Biotechnol. 2007;23:823-32.

26. Rivera-Hoyos CM, Morales-Álvarez ED, Poutou-Piñales RA, Pedroza-Rodríjuez AM, Rodríguez-Vázquez R, Delgado-Boada JM. Fungal laccases. Fungal Biol Rev. 2013;27:67-82

27. Si J, Peng F, Cui B. Purification, biochemical characterization and dye decolorization capacity of an alkali-resistant and metal-tolerant laccase from Trametes pubescens. Bioresour Technol. 2013:128:49-57.

28. Guo LQ, Lin SX, Zheng XB, Huang ZR, Lin JF. Production, purification and characterization of a thermostable laccase from a tropical white-rot fungus. World J Microbiol Biotechnol. 2011;27:731-5

29. Zhu Y, Zhang H, Cao M, Wei Z, Huang F, Gao P. Production of a thermostable metal-tolerant laccase from Trametes versicolor and its application in dye decolorization. Biotechnol Bioprocess Eng. 2011;16:1027-35.

30. Keum YS, Li QX. Fungal laccase-catalyzed degradation of hydroxy polychlorinated biphenyls. Chemosphere. 2004;56:23-30.

31. Liu L, Lin Z, Zheng T, Lin L, Zheng C, Lin Z, et al. Fermentation optimization and characterization of the laccase from Pleurotus ostreatus strain 10969. Enzyme Microb Tech. 2009;44:426-33.

32. Torres E, Bustos-Jaimes I, Le Borgne S. Potential use of oxidative enzymes for the detoxification of organic pollutants. Appl Catal B Environ. 2003;46:1-15.

33. Fang ZM, Li TL, Chang F, Zhou P, Fang W, Hong YZ, et al. A new marine bacterial laccase with chloride-enhancing, alkaline-dependent activity and dye decolorization ability. Bioresour Technol. 2012;111:36-41.

34. Moore BM, Flurkey WH. SDS activation of a plant poly-phenoloxidase. J Biol Chem. 1990;265:4982-8.

35. Miyazaki K. A hyperthermophilic laccase from Thermus thermophilus HB27. Extremophiles. 2005;9:415-25

36. Telke AA, Kadam AA, Jagtap SS, Jadhav JP, Govindwar SP. Biochemical characterization and potential for textile dye degradation of blue laccase from Aspergillus ochraceus NCIM-1146. Biotechnol Bioproc E. 2010;15:696-703.

37. Cabana H, Jones JP, Agathos SN. Preparation and characterization of cross-linked laccase aggregates and their application to the elimination of endocrine disrupting chemicals. J Biotechnol. 2007;132:23-31.

38. Oliva JM, Sáez F, Ballesteros I, González A, Negro MJ, Manzanares P, et al. Effect of lignocellulosic degradation compounds from steam explosion pretreatment on ethanol fermentation by thermotolerant yeast Kluyveromyces marxianus. In: Biotechnology for fuels and chemicals. 2003. p. 141-53.

39. García-Aparicio MP, Ballesteros I, González A, Oliva JM, Ballesteros M, Negro MJ. Effect of inhibitors released during steam-explosion pretreatment of barley straw on enzymatic hydrolysis. In: Twenty-Seventh Symposium on Biotechnology for Fuels and Chemicals. 2006. p. 278-88.

40. Moreno AD, Ibarra D, Ballesteros I, González A, Ballesteros M. Comparing cel viability and ethanol fermentation of the thermotolerant yeast Kluyveromyces marxianus and Saccharomyces cerevisiae on steam-exploded biomass treated with laccase. Bioresour Technol. 2013;135:239-45.

41. Tabka MG, Herpoel-Gimbert I, Monod F, Asther M, Sigoillot JC. Enzymatic saccharification of wheat straw for bioethanol production by a combined cellulase, xylanase and feruloyl esterase treatment. Enzyme Microb Technol. 2006:39:897-902

42. Moreno AD, Ibarra D, Fernández JL, Ballesteros M. Different laccase detoxification strategies for ethanol production from lignocellulosic biomass by the thermotolerant yeast Kluyveromyces marxianus CECT 10875. Bioresour Technol. 2012;106:101-9.

43. Palonen $\mathrm{H}$, Viikari L. Role of oxidative enzymatic treatments on enzymatic hydrolysis of softwood. Biotechnol Bioeng. 2004;86:550-7.

44. Martín C, Galbe M, Wahlbom CF, Hahn-Häerdal B, Jösson JL. Ethanol production from enzymatic hydrolysates of sugarcane bagasse using recombinant xylose-utilising Saccharomyces cerevisiae. Enzyme Microb Technol. 2002;31:274-82. 
45. García-Aparicio MP, Ballesteros I, González A, Oliva JM, Ballesteros M, Negro MJ. Effect of inhibitors released during steam-explosion pretreatment of barley straw on enzymatic hydrolysis. Appl Biochem Biotechnol. 2006;129:278-88.

46. Jonsson LJ, Palmqvist E, Nilvebrant N-O, Hahn-Hagerdal B. Detoxification of wood hydrolysate with laccase and peroxidase from the white-rot fungus Trametes versicolor. Appl Microb Biotechnol. 1998;49:691-7.

47. Rühl M, Majcherczyk A, Kües U. Lcc1 and Lcc5 are the main laccases secreted in liquid cultures of Coprinopsis cinerea strains. Antonie Van Leeuwenhoek. 2013;103:1029-39.

48. Laemmli UK. Cleavage of structural proteins during the assembly of the head of bacteriophage T4. Nature. 1970;227:680-5.

49. Bourbonnais R, Paice MG. Oxidation of non-phenolic substrates: an expanded role for laccase in lignin biodegradation. Febs Lett. 1990;267:99-102

50. Harkin JM, Larsen MJ, Obst JR. Use of syringaldazine for detection of laccase in sporophores of wood rotting fungi. Mycologia. 1974;66:469-76.

51. Benfield G, Bocks SM, Bromley K, Brown B. Studies of fungal and plant laccases. Phytochemistry. 1964;3:79-88.

52. Froehner S, Eriksson K. Properties of the glycoprotein laccase immobilized by two methods. Acta Chem Scand B. 1975;29:691-4

53. Williamson PR. Biochemical and molecular characterization of the diphenol oxidase of Cryptococcus neoformans: identification as a laccase. J Bacteriol. 1994;176:656-64

54. Koroleva O, Gavrilova V, Yavmetdinov I, Shleev S, Stepanova E. Isolation and study of some properties of laccase from the basidiomycetes Cerrena maxima. Biochem (Moscow). 2001;66:618-22.

55. Ji L, Shen $Y, X u$ L, Peng B, Xiao Y, Bao X. Enhanced resistance of Saccharomyces cerevisiae to vanillin by expression of lacA from Trametes sp. AH28-2. Bioresour Technol. 2011;102:8105-9.

56. Folin $\mathrm{O}$, Ciocalteu V. On tyrosine and tryptophane determinations in proteins. J Biol Chem. 1927;73:627-50.

\section{Submit your next manuscript to BioMed Central and take full advantage of:}

- Convenient online submission

- Thorough peer review

- No space constraints or color figure charges

- Immediate publication on acceptance

- Inclusion in PubMed, CAS, Scopus and Google Scholar

- Research which is freely available for redistribution 